\title{
Observations from Using Two Modes of Teaching Undergraduate Computer Architecture
}

\author{
Benjoe A. Juliano, Chi-Hui Chen, and Elena V. Kroumova \\ Department of Computer Science \\ California State University, Chico \\ Chico, CA 95929-0410 \\ $530898-4619$ \\ \{Juliano,CChen,ElenaV\}@ecst.csuChico.edu
}

\begin{abstract}
The authors present observations from using two modes of teaching undergraduate computer architecture. Two sections were taught differently: one section was taught using a traditional classroom setup, while the other section was taught in a classroom equipped for distance education. In the latter, students had the option of attending live lectures on campus, or viewing either live or archived lectures through the Web. The authors analyze and present data gathered from tracking facilities of the online course management tools used to deliver the course. The authors conclude that, overall, the time students spent accessing online lectures is not a significant factor to their final grades.
\end{abstract}

\section{Keywords}

Teaching methods, teaching materials, web-based learning, evaluating learning and teaching, online course delivery and management.

\section{INTRODUCTION}

The Department of Computer Science at California State University, Chico (CSUC) offered two sections of an undergraduate Computer Architecture class (CSCI 171) using two modes of delivery last Fall Semester 2001 [12]. The first section was taught using a traditional classroom setup, while the second section was taught in a classroom equipped for distance education. Students registered for the second section had the option of attending live lectures on campus, or viewing either live or archived lectures via the Web.

Students in both sections had access to WebCT, an online course management system used in CSUC. Quizzes were also administered online through WebCT, but examinations were conducted on campus. Lectures from the second section were archived via HorizonLive, an online course delivery system used in CSUC.

Permission to make digital or hard copies of all or part of this work for personal or classroom use is granted without fee provided that copies are not made or distributed for profit or commercial advantage and that copies bear this notice and the full citation on the first page. To copy otherwise, or republish, to post on servers or to redistribute to lists, requires prior specific permission and/or a fee.

ITiCSE 2003, June 30 - July 2, 2003, Thessaloniki, Greece.

Copyright 2003 ACM 1-58113-000-0/00/0000_..\$5.00.
HorizonLive was also used to deliver live lectures to remote students as the lectures were being archived. These archived lectures were eventually made available to any student registered for the course. Both WebCT and HorizonLive have usage tracking capabilities. Tracking information from these online packages, final student grades, and student evaluations of teaching are analyzed and evaluated to interpret any findings from this dual mode course offering.

\section{REVIEW OF RELATED LITERATURE}

Courses are no longer being offered the way they used to. As Boroni et al. [1,2] and Turner [16] have reported, the advent of the Internet, the Web, advanced browser technology, etc. has changed the way courses are delivered to students. In particular, a growing number of Web-based tools are being used to enhance the learning environment and to enrich one's learning experience.

Dimitriadis et al. [4] reported their experience with a method of collaborative learning where a professor's role is merely as a "helper." Instead of giving lectures, assignments and laboratory work were integrated into projects and case studies, which are the main sources of knowledge for the students. To facilitate this course delivery technique, the BSCW (Basic Support for Cooperative Work) software package was developed and used. BSCW enables document sharing, holding discussions, and has a Synchronous Debate Organizer, a questionnaire generator that guides students through different project phases. It is reported that $64 \%$ of students sustain that they learn more compared to the traditional method of teaching, while $21 \%$ oppose this notion. More than $60 \%$ of the students said they found the BSCW Debate Organizer really helpful.

Kapadia et al. [13] developed an active software portal called PUNCH (Purdue University Network Computing Hubs) to familiarize students with available computer architecture tools and not worry about its complex structure and the amount of resources consumed. PUNCH enables users to access computer architecture simulators and compilers via the Internet. It is widely used in universities such as Arizona State University, Technion in Israel, University of California at Berkley. On top of PUNCH, NETCARE (NETwork-computer for Computer Architecture Research and Education) [8] was developed. NETCARE consists of tools for teaching computer architecture, and other educational 
components such as original tool documentation, local tool documentation, question and answer, exercises, etc. Exercises are meant to facilitate the integration of tools to computer architecture classes. It is reported that NETCARE is widely praised by students due to its friendly interface, and its contribution towards understanding computer architecture concepts.

Djordjevic et al [5,6,7] proposed an integrated environment for teaching computer architecture; it consists of a software package of Integrated Educational Computer System (SPIECS), and a Computer Knowledge Assessment System (CALKAS). Not only does CALKAS test students' knowledge of the experiment prior to and after the laboratory experiment - the instructor can obtain any student's progress using CALKAS. SPIECS consists of simulators that provide graphical representations of computer architecture systems at different hierarchical levels; laboratory experiments are also included in the package. It is reported [5] that "the average grade has roughly improved $20 \%, \ldots$ students show deeper understanding of the topic lectured."

\section{COURSE MANAGEMENT AND DELIVERY}

Undergraduate Computer Architecture (CSCI 171) at CSUC's Department of Computer Science is a 3-unit course. CSCI 171 is part of a 31-unit upper-division core required in both the B.S. in Computer Science and the B.S. in Computer Information Systems degrees offered by the department. CSCI 171 is also a prerequisite for admission to conditionally classified (as opposed to either unclassified or classified) status in the M.S. in Computer Science degree offered by the department. The course's prerequisite is CSCI 51A, Assembly Language Programming. The department has been using Patterson and Hennessy's "Computer Organization and Design" [15] as the course textbook. In Fall 2001, the professor of instruction used the lecture slides that accompany this textbook. These slides were made available to students in Adobe PDF format (one to two slides per page) and in CompuServe GIF (details for the use of this file format will be described later). The professor maintains an online version of the syllabus [11] accompanied by an online resource page [12].

The following features characterized the demographics of the course last Fall 2001. A total of 43 students registered for the course (25 in Section 1 and 18 in Section 2). The two sections were demographically proportional. There were only two female students in Section 1 and one female student in Section 2. The majority of the students in each section had senior standing. The first section had seven students with junior standing, 15 with senior standing, and three who were graduate students. The second section had one sophomore student, five juniors, seven seniors, and five graduate students. The first section had 17 students with a declared major in Computer Science (CSCI), five students with a Computer Information Systems (CINS) major, one Business Administration (BADM) student, one Computer Engineering (CMPE) student, and one Communication Design (CDES) student. The second section had 16 students with CSCI major, one student of CINS, and one Electrical Engineering (ECE) student.

All students had access to WebCT [17], an online course management system used in CSUC. WebCT encompasses teaching and learning tools for course development, course delivery, and course administration. It provides course delivery tools for communication and collaboration (e.g. discussion boards, chat, whiteboard, and e-mail), assessment (e.g. self-tests, surveys, and quizzes with a variety of question types), and selective content release (based on a variety of parameters, such as time or student performance).

Lectures from the Section 2 were archived via HorizonLive [10], an online course delivery system used in CSUC. HorizonLive supports live, web-based collaboration, e-learning, web conferencing, and interactive webcasts through live streaming audio and video. Perhaps the two most impressive HorizonLive features are its eBoard and its LiveApp. HorizonLive's eBoard lets presenters or participants make notes on a content window during a live session. The presenter controls the white boarding function (e.g. which slides to "push" into the eBoard) and decides access to it. Just like a real-world whiteboard, participants and instructors can enter text, draw arrows, draw in free form, select colors and even import images. Archived sessions include the entire whiteboard interaction that took place in the live session. HorizonLive's LiveApp feature facilitates live demonstrations of software applications on the Web. Screen images of the application are treated as lesson slides (to reduce bandwidth, the capture rate is specified by the presenter) that can be "pushed" into the whiteboard feature.

Archived lectures were made available to any student registered for the course. Only two MIPS assembly language programming assignments were given (assembly language programming is a prerequisite of the course). Although nine quizzes were administered online through WebCT (just about an online quiz every week, with scores immediately posted on WebCT's electronic gradebook and "review" versions of the quizzes released after each quiz was graded), examinations were conducted on campus. A midterm exam was administered last October 11, and a final exam on December 20.

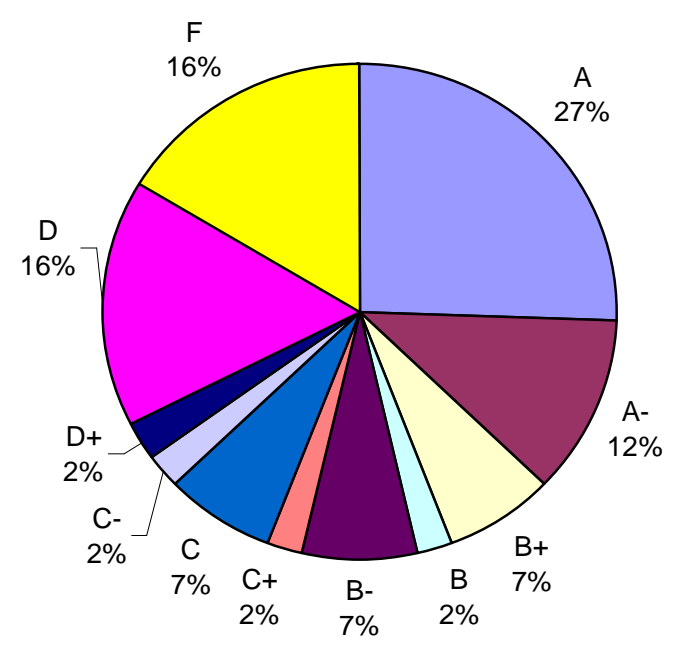

Figure 1. Overall final grade distribution

The lecture slides that accompany the textbook used in teaching CSCI 171 at CSUC last Fall semester 2001 are in Microsoft 


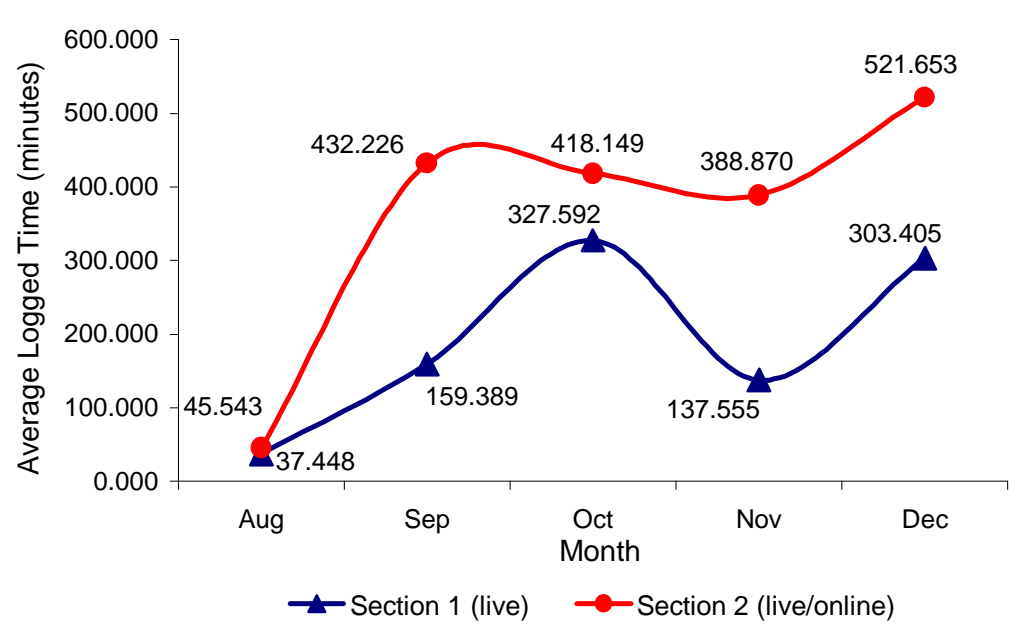

Figure 2. Average monthly logged time per section logged additional hours right before the two exams in October and December, whereas Section 2 students consistently logged more hours from before the first exam to the end of the semester. Figure 3 plots the relationship between the final grades the students earned for the course, and the average weekly logged time on HorizonLive viewing archived lectures. The graph shows a disparity between the average weekly logged times on HorizonLive and the final grade received. There are quite a few students who earned high grades without referencing the archived materials as much as others. Likewise, there are students who logged quite a number of hours online, but still did not earn passing grades by the end of the semester. Perhaps students who passed the course benefited more from the "live" lectures on campus rather than accessing archived lectures. Additionally, logged time on the HorizonLive server does not guarantee that the student is actually viewing lectures online. It is possible that

PowerPoint format. The professor edited these files, incorporating slides containing scanned images of additional figures from the textbook. Adobe PDF versions of the lecture slides were generated and uploaded to a university web server so that students can access copies of the lecture slides for their own use. Additionally, the lecture slides were saved as CompuServe GIF files and used in conjunction with Ginini Technologies Software's SlideViewer 2.3.0 [9] to define a webbased slideshow. SlideViewer is written in Perl (hence, it will probably run on any operating system that supports Perl) and it is easy to set up and maintain. It also includes features like complete control of the look of the slideshow through design templates, image resizing, auto advancement and cycling of slides, and jumping to a specified slide number.

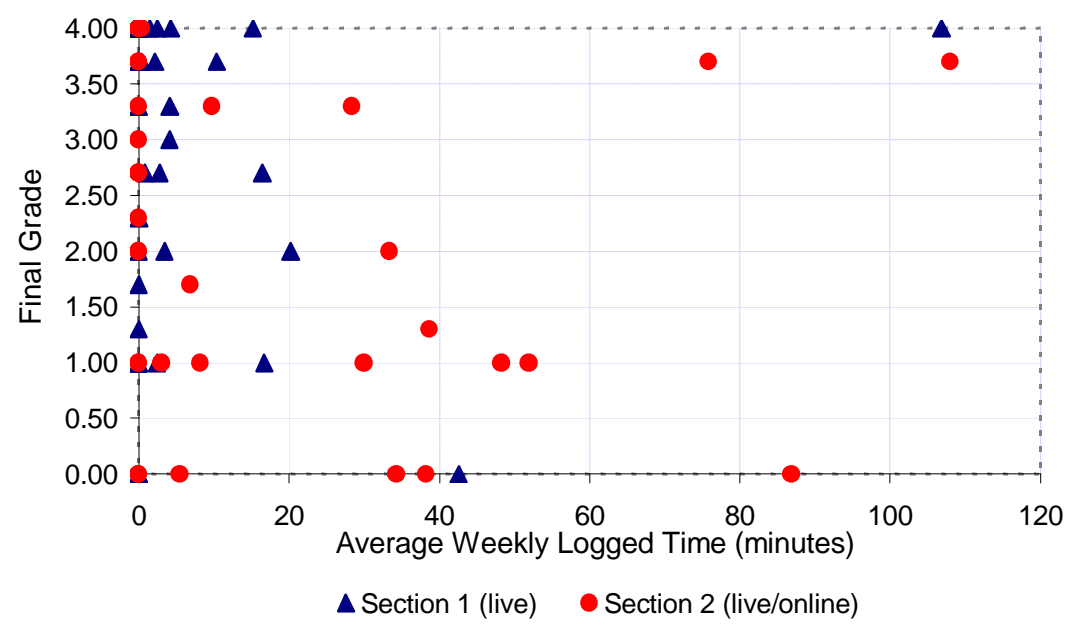

Both WebCT and HorizonLive have usage tracking capabilities. For each student, WebCT tracks the date of first access (indicating when a student signed up for WebCT access to the course), the date of last access, total number of hits, and total number of online articles read and posted. HorizonLive tracks every single access (start time and end time) to online live or archived course materials. Since the WebCT tracking information is not as significant as that provided by HorizonLive, it was not used in this study. HorizonLive's tracking information, results from student evaluations of teaching, and final student grades were collected, analyzed and evaluated to compare and contrast the two course delivery methods used.

\section{RESULTS AND DISCUSSION}

Figure 1 presents the overall final grade distribution (for both sections combined) at the end of the 16-week Fall 2001 semester. A summary of the tracking information gathered from HorizonLive is given in Figure 2. It is clear that students from Section 2 were spending more time with the archived lectures than students from Section 1. Further, students in Section 1 only
Figure 3. Final grades vs. average weekly logged time

students may forget their connection to the server once they have started a session.

Figure 4 details the final grade distribution for each section. Students registered for Section 2 of the course, on average, received lower grades ( 1.78 on a 4.0 scale overall grade, 1.20 for undergraduate students and 3.28 for graduate students) than the students registered for Section 1 (2.79 overall grade, 2.95 for undergraduate and 1.67 for graduate students). Overall, the time the students spent accessing online lectures did not reflect on their final grades for the course. In both sections, the people who failed the course had spent quite a few hours logged into HorizonLive, while the people who earned A's in the course did not spend as much time accessing the online lectures. A distinction can also be made between the undergraduate and graduate students who attended the course. Undergraduate students from both sections who had spent, on average, the most time online failed the course. On the other hand, graduate students' grades are proportional to the time they had spent online. Undergraduate 
students received higher grades in Section 1, whereas graduate students did better in Section 2.

Towards the end of the semester, a Student Evaluation of Teaching (SET) survey was administered. The SET was based on a 5point Likert scale where 5 means "strongly agree" and 1 means "strongly disagree." The mean of the responses to the questions was used by the professor of instruction to interpret how students rated the course overall. The overall mean was 3.79 (3.69 for Section 1 and 3.89 for Section 2). The higher mean for Section 2 seems to indicate that, in general, students in that section were more satisfied with the course compared to students in the other section. Perhaps this could be attributed to the fact that although most of the course activities were well-coordinated and scheduled appropriately, Section 2 students liked having some flexibility in keeping up with the lectures at their own pace.

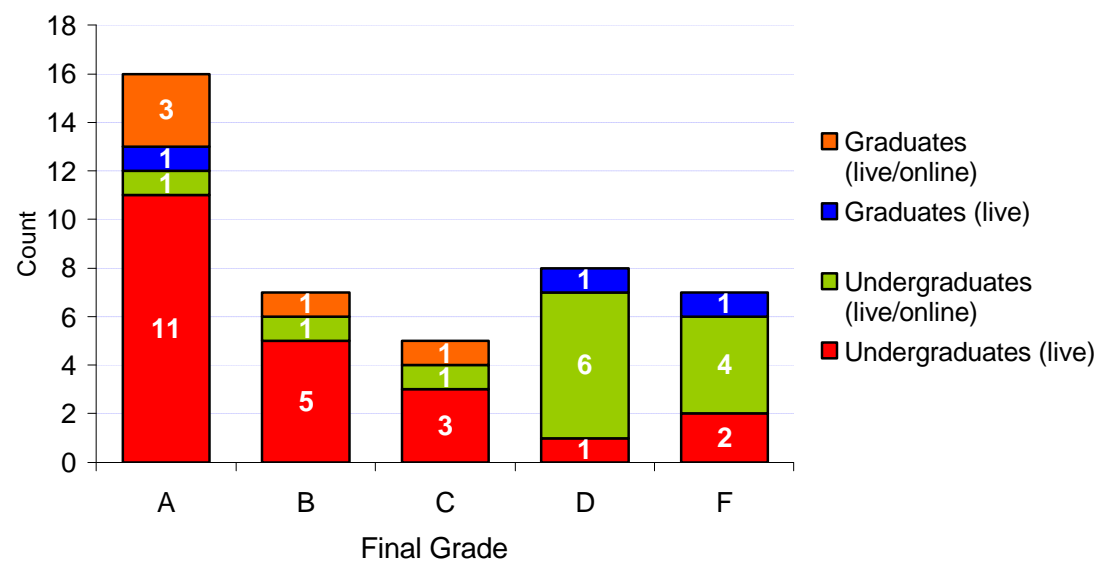

Figure 4. Detail of final grade distribution

Students from both sections also seem to agree (and disagree) over the same SET items. Out of the ten questions in the SET survey, there were two that the students most "agreed" with:

1. My overall knowledge of the subject matter has increased due to the instruction of this course (SET Item \#2, mean 4.5)

2. The instructor is well prepared for class (SET Item \#4, mean 4.3)

The top two items students most "disagreed" with were:

1. The instructor monitors student learning throughout the course (SET Item \#10, mean 3.6)

2. The instructor gives appropriate feedback (SET Item 8, mean 3.7)

It seems that although the students recognized that the professor was well prepared for the class, the professor needs to monitor how much time is spent setting up online materials. Part of this time could have probably been spent with "live" interactions with students. Perhaps one needs to carefully examine how much they rely on technology for things that involve monitoring student progress or providing appropriate feedback to them.
Based on statistics from the data used in this study, the authors concur with work presented by Turner [16]. The professor admits to spending extra time and to putting in a lot of work to place course materials online. Additionally, the authors agree that it may "take even longer for instructors to make the most of web facilities," particularly attributable to the learning curve necessary to work with online course management and delivery packages like WebCT and HorizonLive. The professor claims that administrative chores such as setting up the e-gradebook, setting up an online quiz, etc. are made more complicated by less-than-desirable interfaces and slow Internet connection speeds. Hence, as Turner reports in [16], the authors speculate, "it may be just as effective (or even more effective) to use other alternatives." One potential concern for having lecture slides available online in PDF format is that students may end up using campus printers, instead of personal printers, to print the slides. It may be a while before people are more comfortable reading e-documents through a display unit as opposed to reading hardcopies of the same document.

Likewise, the authors concur with the Lawhead et al. paper [14]. As exemplified by the results presented in this paper, the authors concur that appropriate uses of web-based learning are those "that promote or enhance traditional educational values such as quality, outreach, and flexibility." Educators and administrators, alike, must realize that web-based learning does not work for everyone. CSUC's Department of Computer Science offers Web-based distance education courses that allow individuals to pursue either an undergraduate or graduate degree remotely. The online course offerings use both WebCT and HorizonLive for course management and delivery. To date, it seems that most distance education students are satisfied with this mode of delivery. Perhaps a more in-depth study and analysis would provide a better picture.

Lawhead et al. [14] also point out inappropriate uses of webbased learning are those "that are driven administratively but result in products that are not as good as face-to-face learning." Based on the experience and observation presented in this paper, the authors concur that both educators and administrators must not "perceive web-based learning as a way of relieving professors of the burden of face-to-face or other contact with students." Likewise, educators and administrators must not "perceive that either faculty workload will be reduced or that the same number of faculty can teach a larger number of students." Perhaps Webbased learning works best when the associated faculty workload is appropriately calculated to account for a balance between online and face-to-face interaction.

\section{SUMMARY, CONCLUSIONS, AND RECOMMENDATIONS}

Initially, the authors thought that there would be a noticeable correlation between the amount of time spent accessing online, archived lectures and the students' final grades. The authors observed that, overall, the time the students spent accessing 
online lectures did not reflect on their final grades for the course. Tracking information from online course management and delivery packages must be interpreted carefully, since logged time on a server does not guarantee that the student is actually learning or "working" online. The data from the study presented in this paper also seem to indicate that graduate students benefit more than undergraduates from web-based learning used to promote or enhance the traditional learning environment.

Based on the combined SET results and tracking information used, although students seemed to have learned more of the course material due to the availability of the archived lectures, careful consideration must be given to the balance between online and face-to-face interaction. Additionally, the overhead resulting from setting up, maintaining and updating web-based supplementary materials must also be seriously considered.

\section{REFERENCES}

[1] Boroni, C.M. et al. A paradigm shift: The Internet, the Web, browsers, Java, and the future of computer science education, ACM SIGCSE Bulletin, vol. 30, no. 1, pp. 145-152, March, 1998.

[2] Boroni, C.M. et al. Tying it all together: Creating selfcontained, animated, interactive, web-based resources for computer science education, ACM SIGCSE Bulletin, vol. 31, no. 1, pp. 7-11, March, 1999.

[3] Carbone, A. and Kaasbøll, J.J. A survey of methods used to evaluate computer science teaching, ACM SIGCSE Bulletin, vol. 30, no. 3, pp. 41-45, March, 1998.

[4] Dimitriadis, Y. et al. Cooperative learning in computer architecture: an educational project and its network support, Proc. Frontiers in Education (ASEE/IEEE), pp. 13-18, 2001.

[5] Djordjevic, J., Milenkovic, A., and Grbanovic, N. An integrated environment for teaching computer architecture, IEEE Micro, vol. 20, no. 3, pp. 66-74, May/June, 2000.

[6] Djordjevic, J. et al. CALKAS: A computer architecture learning and knowledge assessment system, IEEE TCCA Newsletter, pp. 26-29, 2000.
[7] Djordjevic, J. et al. An educational environment for teaching a course in computer architecture and organization, Proc. 4th Annual Workshop on Computer Architecture Education, Las Vegas, Nevada, 1998.

[8] Figueiredo, R.J. et al., A network-computing infrastructure for tool experimentation applied to computer architecture education, Proc. Intl. Symposium on Computer Architecture (ISCA), 2000.

[9] Ginini Technologies Software, Slideviewer version 2.3.0. http://www.ginini.com.au/software/slideviewer/ [current 11 Nov. 2002].

[10] HorizonLive, Inc. Experience the most accessible and effective environment for collaboration on the Web. http://www. horizonlive.com [current 11 Nov. 2002].

[11] Juliano, B.A. CSCI 171 with Dr. J, California State University, Chico. http://www.ecst. csuchico.edu/ juliano/csci171 [current 11 Nov. 2002].

[12] Juliano, B.A. Computer Architecture resource page. http:// www.ecst.csuchico.edu/ juliano/Architecture [current 11 Nov. 2002].

[13] Kapadia, N.H., Figueiredo, R.J., and Fortes, J.A.B. PUNCH: A web portal for running tools, IEEE Micro, vol. 20, no. 3, pp. 38-47, May/June, 2000.

[14] Lawhead, P.B. et al. The Web and distance learning: What is appropriate and what is not, Working Group Reports and Supplemental Proc. SIGCSE/SIGCUE, ITiCSE 1997.

[15] Patterson, D.A. and Hennessy, J.L. Computer Organization and Design: The Hardware/Software Interface, $2^{\text {nd }}$ ed., Morgan Kauffman Publishers, San Francisco, California, 1997.

[16] Turner, A.J. Using the Web to enhance education, Proc. Frontiers in Education (ASEE/IEEE), pp. 295-298, 1997.

[17] WebCT, Inc. WebCT.com. http://www.webct.com [current 11 Nov. 2002]. 